\title{
Fate of organic matter in faecal pellets egested by epifaunal mesograzers in a Sargassum forest and implications for biogeochemical cycling
}

\author{
Hiroshi Itoh ${ }^{1,5}$, Masakazu N. Aoki², Yasutaka Tsuchiya ${ }^{2}$, Toshihiko Sato², \\ Hideo Shinagawa ${ }^{2}$, Teruhisa Komatsu ${ }^{3}$, Atsuko Mikami ${ }^{3}$, Takeo Hama ${ }^{4}{ }^{*}$ \\ ${ }^{1}$ Master's Program in Environmental Sciences, University of Tsukuba, Tsukuba, Ibaraki 305-8572, Japan \\ ${ }^{2}$ Shimoda Marine Research Center, University of Tsukuba, Shimoda, Shizuoka 415-0025, Japan \\ ${ }^{3}$ Ocean Research Institute, University of Tokyo, Minamidai, Nakano-ku, Tokyo 164-8639, Japan \\ ${ }^{4}$ Graduate School of Life and Environmental Sciences, University of Tsukuba, Tsukuba, Ibaraki 305-8572, Japan
}

${ }^{5}$ Present address: Forestry Department, Ministry of Agriculture and Fisheries, Camdenpark, St. Vincent \& the Grenadines

\begin{abstract}
Fate of organic matter of the faecal pellets produced by epifaunal mesograzers in a Sargassum forest was elucidated by determination of the organic carbon and nitrogen flux and fatty acid composition of the 3 types of faecal pellets, i.e. fresh, sinking and precipitated. The organic carbon contents of those 3 types averaged 21.4, 6.0 and 5.5\% dry weight, respectively, showing a marked difference between the fresh and sinking types. The same trend was found for their organic nitrogen content. A dissolution-decomposition experiment ascertained the rapid loss of organic matter after the pellets were egested. The ratio of the unsaturated fatty acids to total fatty acids (UFA:TFA) decreased in the order of the fresh, sinking and precipitated pellets, whereas the bacterial biomarker fatty acids increased in that order. The daily sinking fluxes of the faecal pellets were 197 to $639 \mathrm{mg} \mathrm{C}$ and 15 to $53 \mathrm{mg} \mathrm{N} \mathrm{m}^{-2} \mathrm{~d}^{-1}$ for organic carbon and nitrogen, respectively. This flux accounted for 7.4 to $13.4 \%$ (C) and 9.4 to $20.3 \%$ (N) of the primary production in the corresponding season of the Sargassum forest. The estimated residence time of the organic matter in the pellets together with the result of the dissolution-decomposition experiment indicated that about half of the organic carbon and nitrogen egested as faecal pellets was laterally exported to the pelagic zone by the exchange of water. Those possible lateral export fluxes accounted for 4.1 to $7.4 \%$ (C) and 4.4 to $9.5 \%$ (N) of $S a r$ gassum production.
\end{abstract}

KEY WORDS: Faecal pellet · Mesograzer $\cdot$ Sinking flux $\cdot$ Sargassum forest $\cdot$ Biogeochemical cycle

\section{INTRODUCTION}

The biogeochemical roles of the faecal pellets of zooplankton in the ocean have been widely recognized. The rapid vertical transport of biogenic elements from the euphotic layer to deeper layers is one of the most important biogeochemical functions of faecal pellets in the ocean system (Turner 2002, Frangoulis et al. 2005). This process likely functions as a main mechanism of the biological pump which works to accomplish the sequestration of carbon dioxide supplied by human activity (Sundquist 1993). Over the past few decades, a considerable number of studies using sediment traps in both pelagic and coastal waters have been conducted on zooplankton faecal pellets. However, there has been no study that attempted to elucidate the biogeochemical roles of faecal pellets in seaweed beds in the coastal zone.

Seaweed is responsible for a considerable portion of primary production in coastal zones (Alongi 1998, Sand-Jensen \& Nielsen 2004). Sargassum, as well as kelp, is one of the important seaweed groups that construct dense forests (Alongi 1998). It is well known that a seaweed ecosystem provides habitat for various 
kinds of fauna (Norton \& Benson 1983, Brawley 1992, Edgar \& Aoki 1993, Tanaka \& Leite 2003). Although ecological studies of epifaunal mesograzers have addressed topics such as their grazing activity and its impact on their host plants (Norton \& Benson 1983, Duffy 1990), little attention has been given to their roles in the bioelemental cycle both within and outside the seaweed forest ecosystems (Edgar \& Moore 1986, Taylor 1998, Taylor \& Rees 1998). Since the usual densities of mesograzer groups reportedly exceed thousands of individuals $\mathrm{m}^{-2}$ (Brawley 1992, Taylor 1998), it is likely that they play important roles in the biogeochemical cycle in Sargassum forests. The formation of layers of precipitated faecal pellets on the sea floor in a seaweed forest is one of the visible signs of their substantial biogeochemical importance. However, the dynamics of the faecal pellets of mesograzers and their important biogeochemical functions have not yet been systematically studied.

One possible function is the recycling of biological elements by supplying organic compounds to microbes. Considerable amounts of the organic compounds in fresh faecal pellets are reported to be rapidly dissolved after they are egested (Lee \& Fisher 1994, Urban-Rich 1999). Dissolved organic matter (DOM) released from the pellets appears to be mainly composed of compounds labile to microbial attack, making it likely that the released DOM supports microbial growth. Thus, the grazing and egestion of the faecal pellets by epifaunal mesograzers probably accelerates the nutrient cycle in seaweed beds. Another possible function of the pellets is to transport the bioelements beyond the seaweed beds. Organic matter that is not dissolved and decomposed within a few days after the pellets are egested tends to remain within the pellets for a weeks to months (Lee \& Fisher 1994, Urban-Rich 1999). When faecal pellets on the sea floor of seaweed beds are resuspended into the water column by rough water conditions, they may be laterally carried outside the seaweed beds, swept along in the exchange of water across the ecosystem boundary. In this case, the pellets can be regarded as potential carriers of bioelements from coastal waters to the pelagic ocean. These possible biogeochemical functions of the faecal pellets of epifaunal herbivores in seaweed beds have never been quantitatively estimated.

To elucidate these biogeochemical roles, it is indispensable to know the decomposition process of the faecal pellets of mesograzers. For planktonic copepods, faecal pellets decrease in organic content through microbial decomposition processes (Cowie \& Hedges 1996, Urban-Rich 1999) such as sinking through the water column and precipitation on the sediment surface. In addition to the elemental compo- sition, fatty acid composition is a useful tool to assess the degradation status of faecal pellets. The determination of fatty acid composition of the sinking faecal pellets of zooplankton has shown that polyunsaturated fatty acids (PUFA), which contain more than 2 carboncarbon double bonds, and monounsaturated fatty acids (MUFA), which contain 1 double bond, were more susceptible to microbial attack than saturated fatty acids (SFA), which have no double bond (Wakeham \& Lee 1993, Fileman et al. 1998). Thus, the contribution of unsaturated fatty acids (UFA) composed of PUFA and MUFA likely decreases with the progress of the decomposition of the organic matter after egestion, accompanied with the concomitant increase in SFA contents. It is notable that particular fatty acids such as 15:0 (carbon:double bond), iso15:0, anteiso15:0 and 17:0 are specific to bacteria (Boschker et al. 1999, Graeve et al. 2001). The contribution of these bacterial specific fatty acids (BACFA) to total fatty acid (TFA) content in faecal pellets provides information on the bacterial amount in faecal pellets. Thus, the fatty acid composition as well as the contents of organic carbon and nitrogen can distinguish the degradation status of the organic matter of faecal pellets.

In the present study, we collected all 3 types of faecal pellets (fresh, sinking and precipitated on sediment surface) of epifaunal mesograzers living in a Sargassum forest. Organic carbon and nitrogen content and fatty acid composition were determined for these pellets as well as for the whole body of mesograzers and $S$. ringgoldianum, the dominant species in Sargassum forests at our study site, to assess the compositional changes involved in the egesting, sinking and precipitating processes. A dissolution-decomposition experiment was carried out to elucidate the loss rate of organic carbon and nitrogen from the pellets, and the change in the fatty acid composition after being egested. The sinking flux of the pellets was compared with the primary production of the Sargassum forest to clarify the biogeochemical role of the faecal pellets of mesograzers. In addition, the export fluxes of organic carbon and nitrogen beyond the Sargassum forest were also estimated.

\section{MATERIALS AND METHODS}

Study site. The present study was carried out in Oura Bay, located in Shimoda, Shizuoka, Japan (Fig. 1). Sargassum species, mainly composed of $S$. ringgoldianum Harvey, S. horneri (Turner) Agardh, and S. patens Agardh, cover the sea floor at depths of 1 to $4 \mathrm{~m}$, and Eisenia bicyclis Setchell and Ecklonia cava Kjellman are distributed over the sea floor at depths of more than $4 \mathrm{~m}$ (Yokohama et al. 1987, Mikami 2007). The 

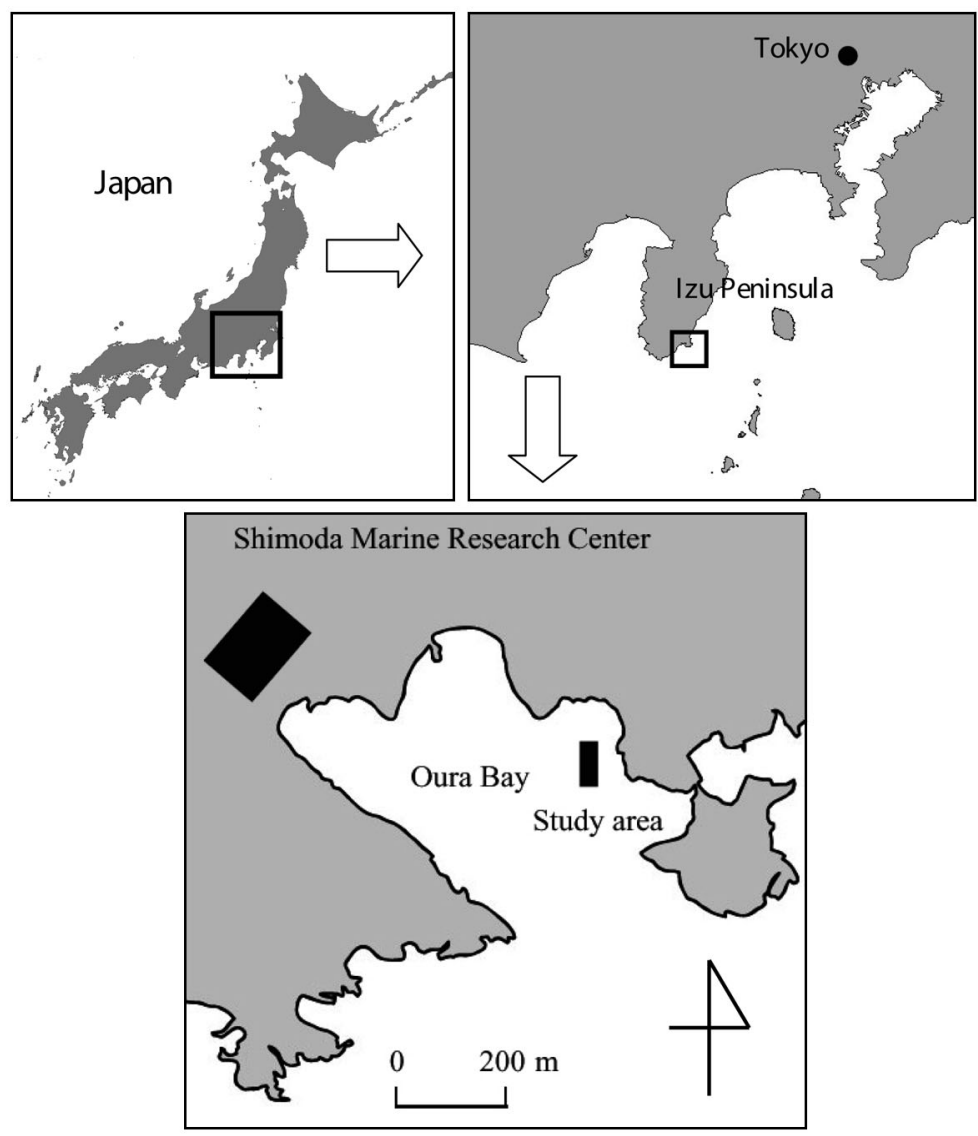

Fig. 1. Station location in Oura Bay, Izu Peninsula, Shizuoka, Japan sinking and the precipitated faecal pellets were collected in the Sargassum forest dominated by $S$. ringgoldianum.

Fresh faecal pellets. The field observations were carried out 4 times, 25 October to 4 November 2004 (autumn hereafter), 31 January to 4 February 2005 (winter), 17 to 20 May 2005 (spring) and 29 August to 2 September (summer) 2005. A few Sargassum ringgoldianum individuals were collected together with the epifaunal mesograzer population. $S$. ringgoldianum was gently washed with seawater to remove detritus and then cultured with the mesograzer population in a container filled by filtered sea water. The culture was continued for $1 \mathrm{~d}$, and the contents of the container were filtered through a sieve $(250 \mu \mathrm{m})$ to remove the algal debris and mesograzers. After the isolation of the faecal pellets was confirmed using a stereoscopic microscope (Fig. 2a), the pellets were filtered onto the precombusted $\left(450^{\circ} \mathrm{C}, 4 \mathrm{~h}\right)$ glass fiber filters (Whatman GF/F), which were pre-weighed. Filter samples were stored at $-20^{\circ} \mathrm{C}$ until analysis.

Sinking faecal pellets. The faecal traps were positioned on the sea floor to collect the sinking faecal pellets. Two cylindrical containers $(95 \mathrm{~mm}$ internal diameter and
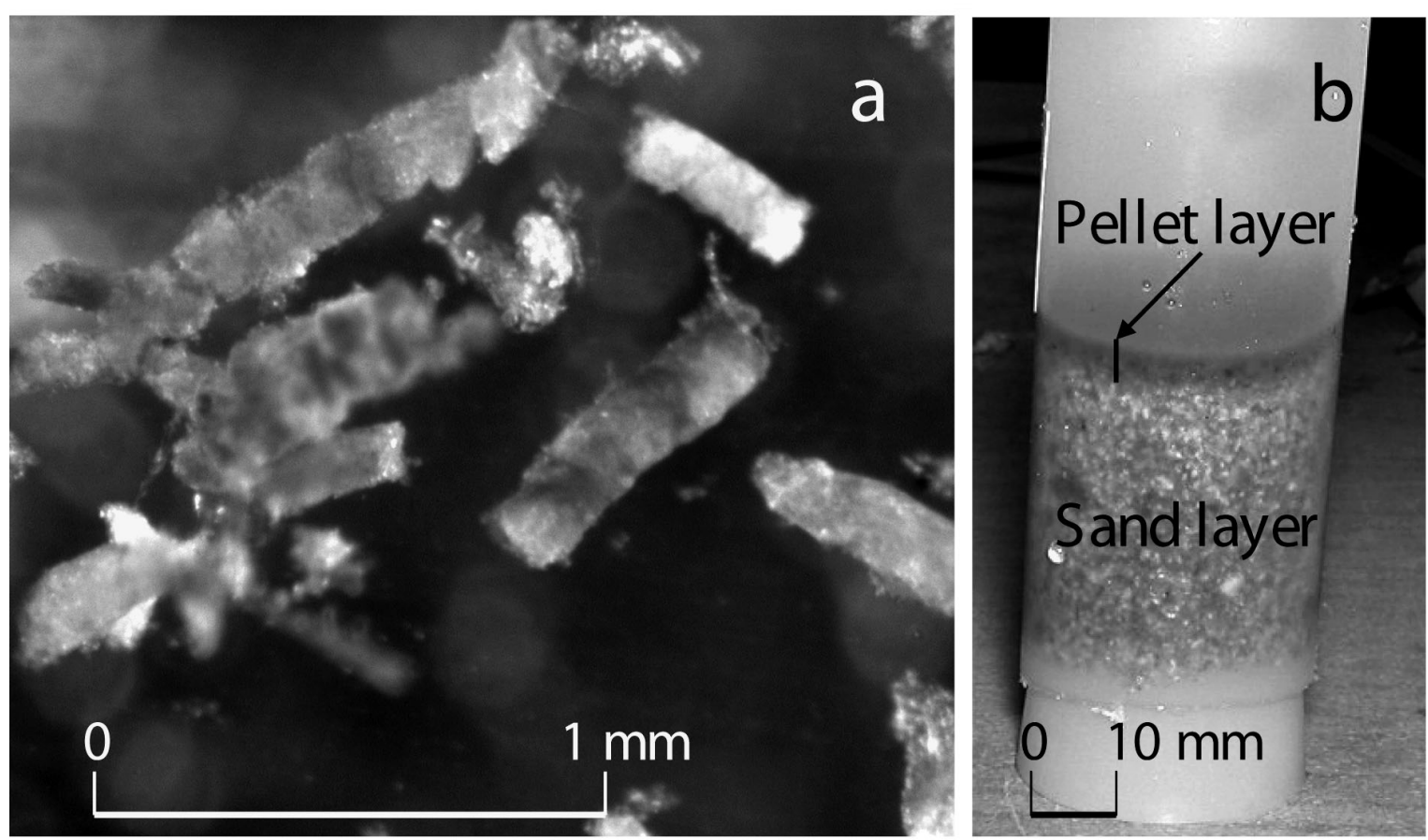

Fig. 2. (a) Isolated fresh faecal pellets of mesograzers. Samples collected from culture of mesograzers with Sargassum ringgoldianum Harvey. (b) Sediment core sample collected below Sargassum 
$170 \mathrm{~mm}$ in length) fixed to a concrete block $(300 \times 300 \times$ $60 \mathrm{~mm}$ ) were used as traps. Five sets of traps were arranged along a fixed line in the Sargassum forest by SCUBA divers, who were careful not to resuspend the surface sediment. The water depths where the traps were placed varied from 4.4 to $8.8 \mathrm{~m}$. The traps were recovered after 2 to $3 \mathrm{~d}$, and their contents were filtered through a sieve ( $250 \mu \mathrm{m}$ mesh) to remove pebbles and bits of seaweed. Additional sieving ( $88 \mu \mathrm{m}$ mesh) was needed to isolate faecal pellets contaminated by sand particles and pellets on the mesh were filtered through $\mathrm{GF} / \mathrm{F}$ and stored at $-20^{\circ} \mathrm{C}$ until analysis.

Precipitated faecal pellets. Faecal pellets precipitated on the surface of the Sargassum forest sediment were collected by a small corer (28 $\mathrm{mm}$ diameter), which a SCUBA diver inserted a few centimetres into the sediment. Ten core samples were collected in each observation. The faecal pellet layer, which had covered the surface of the sediment to a depth of several millimetres (Fig. 2b), was carefully removed from the core sample. After the pellets were isolated, they were filtered through $\mathrm{GF} / \mathrm{F}$ that were then stored at $-20^{\circ} \mathrm{C}$.

Dissolution-decomposition experiment. The fresh faecal pellets produced during the culture experiments of epifaunal mesograzers with Sargassum ringgoldianum on 1-2 November 2005 were used for a dissolution-decomposition experiment. The pellets were suspended in GF/F-filtered seawater in fourteen $125 \mathrm{ml}$ polycarbonate bottles immediately after their collection. The incubation bottles were stored in the dark at $20^{\circ} \mathrm{C}$. At specific intervals $(0,1,2.5,6,13$ and $20 \mathrm{~d})$, the contents of 2 bottles were filtered through GF/F. Combining 2 bottles was necessary due to low pellet biomass. Samples collected on Days 0, 1, 2.5, 6, 13 and 20 were used for analyses of the contents of organic carbon and nitrogen, and those on Days 0, 2.5 and 20 for an analysis of fatty acid composition. Length and width of about 20 intact pellets were measured under a binocular microscope, and their volume was estimated assuming that the pellets were cylindrical. A little change in the pellet size was observed microscopically, but the accurate size was not measured on Days 2.5 and 20. Thus, we assumed that the pellet volume did not change throughout the experiment to calculate the organic carbon and nitrogen contents per pellet volume.

Analyses of organic carbon and nitrogen. The faecal pellets on the GF/F were analyzed for dry weight, organic carbon and nitrogen content. Filters were dried in a vacuum desiccator until their weights became constant, and the dry weight was then measured. The amounts of organic carbon and nitrogen were determined by an elemental analyzer (EA1108, Fisons). Samples other than pellets, such as Sargassum ringgoldianum and mesograzers, were also subjected to a determination of organic carbon and nitrogen content, once they were ground into powder. Duplicate samples were used for that determination, except for dissolution-decomposition samples, in which only a single sample was analyzed due to the low biomass. The analytical error was generally within $5 \%$.

Analysis of fatty acid composition. Lipid materials were extracted from the pellet samples, Sargassum ringgoldianum and mesograzers by chloroform/methanol (2:1). After the chloroform fraction was separated from the methanol fraction by adding $\mathrm{H}_{2} \mathrm{O}$, methyl esters of fatty acids were obtained using HCl-methanol, and the concentrations of fatty acids were determined by a gas chromatograph (HP 6800, Agilent) according to the analytical conditions shown in Hama (1991). A gas chromatograph/mass spectrometer (Voyager, Thermoelectron) was used for the identification of fatty acids, and the concentrations of 17 fatty acids were determined. The concentrations were usually determined for duplicate samples (the margin of error for each sample was generally within $7 \%$; Hama 1991). The concentrations of SFA (sum of 14:0, 16:0, 18:0, 20:0 and 22:0),

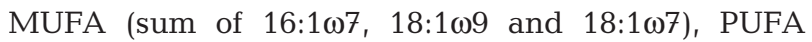

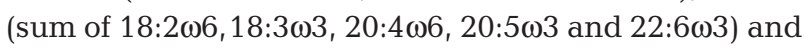
BACFA (sum of 15:0, iso15:0, anteiso15:0 and 17:0) are shown instead of those of the individual fatty acid, because the fatty acid composition will not be discussed in detail.

\section{RESULTS}

\section{Environmental conditions}

The surface water temperature at the sampling site varied from 15.1 to $24.7^{\circ} \mathrm{C}$. The faecal trap experiments were carried out during calm conditions to avoid resuspension of the precipitated particles on the sea floor. The average wind speed, measured at the Irozaki Meteorological Station located about $12 \mathrm{~km}$ southwest of the experimental site, varied in the ranges of $3.1-5.9,5.3-9.0,2.8-4.9$ and $1.7-2.4 \mathrm{~m} \mathrm{~s}^{-1}$, in autumn, winter, spring and summer, respectively. Although relatively high wind speeds were noticed during the trap experiments in winter, the speeds were low in other seasons.

\section{Organic carbon and nitrogen contents}

The contents of the organic carbon and nitrogen per dry weight of the faecal pellets are shown in Table 1. Because dry weights were not measured with sufficient accuracy for the fresh faecal pellets in spring or for the sinking and precipitated pellets in autumn, 
their values are not shown. The organic carbon content of the fresh pellets showed the highest values among the pellets, i.e. in the range of 19.3 to $22.5 \%$ dry weight (mean $=21.4 \%)$. The organic carbon contents of sinking faecal pellets were less than one third of the fresh pellets, i.e. in the range of 4.6 to $8.2 \%$, similar to values obtained in the precipitated pellets which had a mean value of $5.5 \%$ dry weight. No seasonal variation was observed in the organic carbon content of the precipitated pellets.

The organic nitrogen content per dry weight also showed the highest values in the fresh faecal pellets, with a mean of $3.43 \%$ dry weight, whereas lower organic nitrogen contents were found for the sinking and precipitated pellets with mean values of 0.56 and $0.48 \%$, respectively.

The C:N ratio also showed a considerable variation among the pellets. The lowest C:N ratio was calculated for fresh faecal pellets (5.5 to 7.7), whereas higher ratios were found for the sinking (9.8 to 12.2 ) and precipitated pellets (8.5 to 14.3 ).

\section{Fatty acid composition}

To elucidate the degradation stage and concentration of bacteria, only the composition of SFA, MUFA, PUFA and BACFA are shown in Table 2, though their detailed composition has been determined. In all 3 types of faecal pellets, SFA was found to be a major component, averaging from 50.9 to $66.3 \%$ of the total fatty acid composition. The contribution of SFA was lowest in the fresh pellets and higher in the sinking and precipitated pellets. MUFA was the second most important group in all pellets, with a high contribution of $36.9 \%$ found in the fresh pellets in contrast to SFA. There was little contribution found for PUFA, and the difference in the contribution among pellet types was

Table 1. Organic carbon and nitrogen contents (\% dry weight) and C:N ratio of the fresh, sinking and precipitated faecal pellets (mean $\pm \mathrm{SD}$ ). Nine (autumn) and 5 (winter and summer) samples were used for fresh faecal pellet, and 10 samples for sinking and precipitated pellets

\begin{tabular}{|c|c|c|c|c|c|c|c|c|c|}
\hline \multirow[t]{2}{*}{ Season } & \multicolumn{3}{|c|}{ — Fresh faecal pellet } & \multicolumn{3}{|c|}{ — Sinking faecal pellet —ـ } & \multicolumn{3}{|c|}{ - Precipitated faecal pellet - } \\
\hline & $\begin{array}{l}\text { Organic } \\
\text { carbon }\end{array}$ & $\begin{array}{l}\text { Organic } \\
\text { nitrogen }\end{array}$ & $\mathrm{C}: \mathrm{N}$ & $\begin{array}{c}\text { Organic } \\
\text { carbon }\end{array}$ & $\begin{array}{l}\text { Organic } \\
\text { nitrogen }\end{array}$ & $\mathrm{C}: \mathrm{N}$ & $\begin{array}{l}\text { Organic } \\
\text { carbon }\end{array}$ & $\begin{array}{l}\text { Organic } \\
\text { nitrogen }\end{array}$ & $C: N$ \\
\hline Autumn & $\begin{array}{c}22.4 \\
( \pm 4.4)\end{array}$ & $\begin{array}{c}2.92 \\
( \pm 0.53)\end{array}$ & $\begin{array}{c}7.7 \\
( \pm 1.2)\end{array}$ & - & - & - & - & - & - \\
\hline Winter & $\begin{array}{c}19.3 \\
( \pm 3.9)\end{array}$ & $\begin{array}{c}3.28 \\
( \pm 0.75)\end{array}$ & $\begin{array}{c}5.9 \\
( \pm 0.4)\end{array}$ & $\begin{array}{c}5.2 \\
( \pm 0.61)\end{array}$ & $\begin{array}{c}0.43 \\
( \pm 0.08)\end{array}$ & $\begin{array}{c}12.2 \\
( \pm 1.3)\end{array}$ & $\begin{array}{c}5.6 \\
( \pm 0.65)\end{array}$ & $\begin{array}{c}0.43 \\
( \pm 0.06)\end{array}$ & $\begin{array}{c}13.4 \\
( \pm 1.1)\end{array}$ \\
\hline Spring & - & - & - & $\begin{array}{c}8.2 \\
( \pm 1.3)\end{array}$ & $\begin{array}{c}0.83 \\
( \pm 0.17)\end{array}$ & $\begin{array}{c}9.8 \\
( \pm 0.7)\end{array}$ & $\begin{array}{c}5.5 \\
( \pm 0.67)\end{array}$ & $\begin{array}{c}0.65 \\
( \pm 0.09)\end{array}$ & $\begin{array}{c}8.5 \\
( \pm 1.1)\end{array}$ \\
\hline Summer & $\begin{array}{c}22.5 \\
( \pm 4.2)\end{array}$ & $\begin{array}{c}4.08 \\
( \pm 0.45)\end{array}$ & $\begin{array}{c}5.5 \\
( \pm 0.5)\end{array}$ & $\begin{array}{c}4.6 \\
( \pm 0.93)\end{array}$ & $\begin{array}{c}0.42 \\
( \pm 0.10)\end{array}$ & $\begin{array}{c}11.0 \\
( \pm 1.0)\end{array}$ & $\begin{array}{c}5.4 \\
( \pm 1.0)\end{array}$ & $\begin{array}{c}0.38 \\
( \pm 0.09)\end{array}$ & $\begin{array}{c}14.3 \\
( \pm 1.7)\end{array}$ \\
\hline Mean & $\begin{array}{c}21.4 \\
( \pm 1.8)\end{array}$ & $\begin{array}{c}3.43 \\
( \pm 0.59)\end{array}$ & $\begin{array}{c}6.4 \\
( \pm 1.2)\end{array}$ & $\begin{array}{c}6.0 \\
( \pm 1.9)\end{array}$ & $\begin{array}{c}0.56 \\
( \pm 0.23)\end{array}$ & $\begin{array}{c}11.0 \\
( \pm 1.2)\end{array}$ & $\begin{array}{c}5.5 \\
( \pm 0.1)\end{array}$ & $\begin{array}{c}0.48 \\
( \pm 0.14)\end{array}$ & $\begin{array}{c}12.1 \\
( \pm 3.1)\end{array}$ \\
\hline
\end{tabular}

Table 2. Fatty acid composition of the faecal pellets (\% of total fatty acids). See 'Materials and methods: Analysis of fatty acid composition' for description of saturated fatty acids (SFA), monounsaturated fatty acids (MUFA), polyunsaturated fatty acids (PUFA), and bacterial marker fatty acids (BACFA). Five (fresh faecal pellet) and 10 samples (sinking and precipitated pellets) for each season are shown (mean $\pm \mathrm{SD})$

\begin{tabular}{|c|c|c|c|c|c|c|c|c|c|c|c|c|}
\hline \multirow[t]{2}{*}{ Season } & \multicolumn{4}{|c|}{$\longrightarrow$ Fresh faecal pellet -} & \multicolumn{4}{|c|}{ Sinking faecal pellet } & \multicolumn{4}{|c|}{ — Precipitated faecal pellet } \\
\hline & SFA & MUFA & PUFA & BACFA & SFA & MUFA & PUFA & BACFA & SFA & MUFA & PUFA & BACFA \\
\hline Autumn & $\begin{array}{c}58.9 \\
( \pm 8.7)\end{array}$ & $\begin{array}{c}27.5 \\
( \pm 4.3)\end{array}$ & $\begin{array}{c}5.0 \\
( \pm 1.4)\end{array}$ & $\begin{array}{c}8.6 \\
( \pm 0.1)\end{array}$ & $\begin{array}{c}57.4 \\
( \pm 7.1)\end{array}$ & $\begin{array}{c}26.0 \\
( \pm 5.1)\end{array}$ & $\begin{array}{c}10.3 \\
( \pm 3.4)\end{array}$ & $\begin{array}{c}6.3 \\
( \pm 1.2)\end{array}$ & $\begin{array}{c}70.3 \\
( \pm 5.8)\end{array}$ & $\begin{array}{c}14.9 \\
( \pm 2.2)\end{array}$ & $\begin{array}{c}3.0 \\
( \pm 0.4)\end{array}$ & $\begin{array}{c}11.8 \\
( \pm 1.4)\end{array}$ \\
\hline Winter & $\begin{array}{c}48.3 \\
( \pm 3.4)\end{array}$ & $\begin{array}{c}38.8 \\
( \pm 7.0)\end{array}$ & $\begin{array}{c}6.1 \\
( \pm 1.3)\end{array}$ & $\begin{array}{c}6.8 \\
( \pm 0.9)\end{array}$ & $\begin{array}{c}57.7 \\
( \pm 6.6)\end{array}$ & $\begin{array}{c}28.8 \\
( \pm 4.9)\end{array}$ & $\begin{array}{c}5.2 \\
( \pm 1.2)\end{array}$ & $\begin{array}{c}8.3 \\
( \pm 1.6)\end{array}$ & $\begin{array}{c}70.6 \\
( \pm 5.6)\end{array}$ & $\begin{array}{c}15.2 \\
( \pm 1.4)\end{array}$ & $\begin{array}{c}4.7 \\
( \pm 1.6)\end{array}$ & $\begin{array}{c}9.5 \\
( \pm 1.6)\end{array}$ \\
\hline Spring & $\begin{array}{c}41.1 \\
( \pm 5.9)\end{array}$ & $\begin{array}{c}47.5 \\
( \pm 5.6)\end{array}$ & $\begin{array}{c}4.3 \\
( \pm 0.8)\end{array}$ & $\begin{array}{c}7.1 \\
( \pm 2.2)\end{array}$ & $\begin{array}{c}60.6 \\
( \pm 6.6)\end{array}$ & $\begin{array}{c}27.5 \\
( \pm 3.6)\end{array}$ & $\begin{array}{c}7.1 \\
( \pm 1.4)\end{array}$ & $\begin{array}{c}4.8 \\
( \pm 0.9)\end{array}$ & $\begin{array}{c}63.9 \\
( \pm 6.3)\end{array}$ & $\begin{array}{c}21.5 \\
( \pm 2.4)\end{array}$ & $\begin{array}{c}6.7 \\
( \pm 1.0)\end{array}$ & $\begin{array}{c}7.9 \\
( \pm 1.2)\end{array}$ \\
\hline Summer & $\begin{array}{c}55.2 \\
( \pm 5.7)\end{array}$ & $\begin{array}{c}33.7 \\
( \pm 5.2)\end{array}$ & $\begin{array}{c}6.3 \\
( \pm 0.7)\end{array}$ & $\begin{array}{c}4.8 \\
( \pm 0.6)\end{array}$ & $\begin{array}{c}63.1 \\
( \pm 6.7)\end{array}$ & $\begin{array}{c}25.1 \\
( \pm 4.5)\end{array}$ & $\begin{array}{c}3.8 \\
( \pm 0.6)\end{array}$ & $\begin{array}{c}8.0 \\
( \pm 1.3)\end{array}$ & $\begin{array}{c}60.8 \\
( \pm 4.7)\end{array}$ & $\begin{array}{c}26.0 \\
( \pm 4.8)\end{array}$ & $\begin{array}{c}5.2 \\
( \pm 0.7)\end{array}$ & $\begin{array}{c}8.0 \\
( \pm 1.3)\end{array}$ \\
\hline Mean & $\begin{array}{c}50.9 \\
( \pm 7.9)\end{array}$ & $\begin{array}{c}36.9 \\
( \pm 8.5)\end{array}$ & $\begin{array}{c}5.4 \\
( \pm 0.9)\end{array}$ & $\begin{array}{c}6.8 \\
( \pm 1.6)\end{array}$ & $\begin{array}{c}59.7 \\
( \pm 2.7)\end{array}$ & $\begin{array}{c}26.9 \\
( \pm 1.6)\end{array}$ & $\begin{array}{c}6.5 \\
( \pm 2.8)\end{array}$ & $\begin{array}{c}6.9 \\
( \pm 1.6)\end{array}$ & $\begin{array}{c}66.3 \\
( \pm 4.8)\end{array}$ & $\begin{array}{c}19.4 \\
( \pm 5.3)\end{array}$ & $\begin{array}{c}4.9 \\
( \pm 1.5)\end{array}$ & $\begin{array}{c}9.3 \\
( \pm 1.8)\end{array}$ \\
\hline
\end{tabular}


not obvious. The contribution of BACFA ranged from 6.8 to $9.3 \%$, and tended to increase in concentration from the fresh to sinking and then precipitated pellets.

\section{Sinking flux and precipitated amounts}

The carbon flux of pellets into the faecal trap varied from 197 to $639 \mathrm{mg} \mathrm{C} \mathrm{m}^{-2} \mathrm{~d}^{-1}$ as a mean value of 5 sets of traps in each season (Fig. 3). Values less than $250 \mathrm{mg} \mathrm{C}$ $\mathrm{m}^{-2} \mathrm{~d}^{-1}$ were obtained in autumn and spring, with values ranging higher than $500 \mathrm{mg} \mathrm{C} \mathrm{m}^{-2} \mathrm{~d}^{-1}$ in winter and summer. In the low flux season, the variation among traps was also minimal, and the standard deviation among 5 traps accounted for 35 and $36 \%$ of the mean values in autumn and spring, respectively. In the high flux season, on the other hand, distinctive variations of flux were found in each trap. Faecal traps were settled along a fixed line in the Sargassum forest and the relatively lower flux was generally measured in the trap settled near the edge of the forest. Somewhat comparable seasonal changes were observed for the nitrogen flux: values less than $25 \mathrm{mg} \mathrm{N} \mathrm{m}^{-2} \mathrm{~d}^{-1}$ in autumn and spring, and high values above $45 \mathrm{mg} \mathrm{N} \mathrm{m}^{-2} \mathrm{~d}^{-1}$ in winter and summer. The variation among traps was not conspicuous in autumn and spring as observed in the carbon flux.

The mean concentration of organic carbon in the precipitated faecal pellets varied from 3.5 to $14.0 \mathrm{~g} \mathrm{C}$ $\mathrm{m}^{-2}$, reaching a minimum in winter and a maximum in summer (Fig. 4). The difference in the concentration

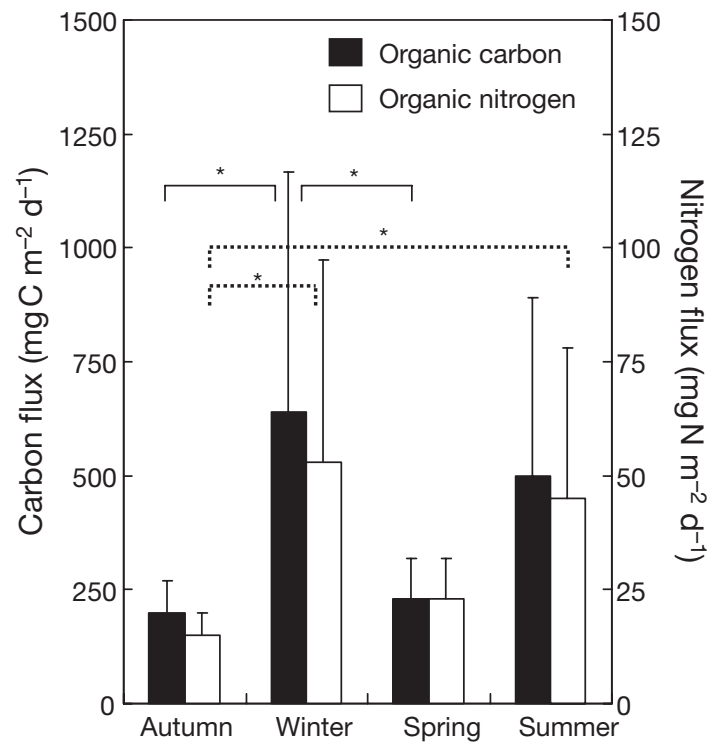

Fig. 3. Organic carbon and organic nitrogen fluxes in faecal pellets collected in traps placed on sea floor of Sargassum forest in Oura Bay. Values show seasonal means $( \pm \mathrm{SD})$ of 5 sediment traps. Multiple comparisons between groups were made by SNK tests (solid comparison lines: C content; dotted comparison lines: $\mathrm{N}$ content). ${ }^{*} 0.05<\mathrm{p}<0.1$

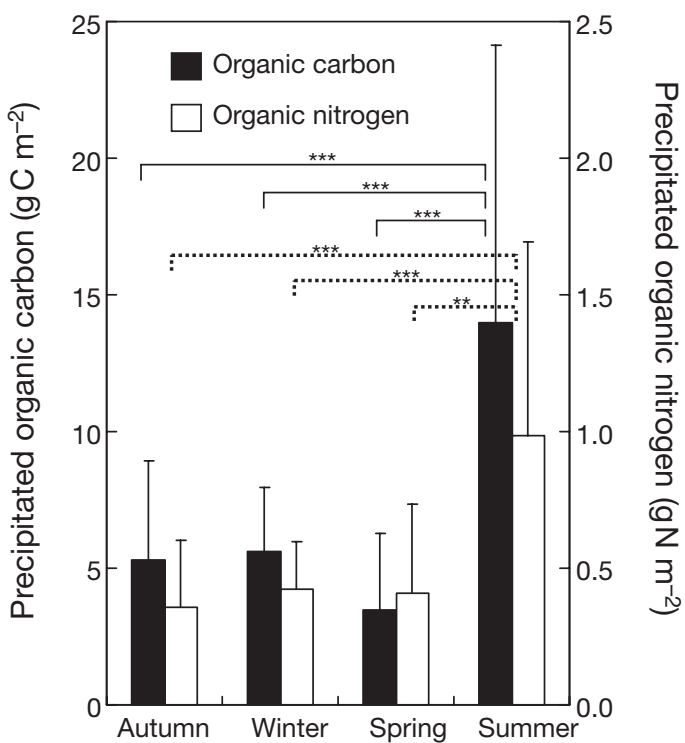

Fig. 4. Concentrations of organic carbon and organic nitrogen in faecal pellets precipitated on sea floor of Sargassum forest in Oura Bay. Values show seasonal means $( \pm \mathrm{SD})$ of 10 core samples. Multiple comparisons between groups were made by SNK tests (solid comparison lines: C content; dotted comparison lines: $\mathrm{N}$ content). ${ }^{* *} 0.01<\mathrm{p}<0.05{ }^{* * *} \mathrm{p}<0.01$

from autumn to spring should be negligible, but the concentration in summer was nearly 3 times higher than those in the other seasons. Almost the same seasonal variation was found for the organic nitrogen in precipitated pellets, ranging from 0.36 to $0.98 \mathrm{~g} \mathrm{~N} \mathrm{~m}^{-2}$. The average values throughout the 4 seasons were $7.1 \mathrm{~g} \mathrm{C} \mathrm{m}^{-2}$ and $0.54 \mathrm{~g} \mathrm{~N} \mathrm{~m}^{-2}$ for organic carbon and organic nitrogen, respectively.

\section{Dissolution-decomposition experiment}

The time changes in organic carbon and nitrogen content during the dissolution-decomposition experiment are shown per pellet volume $\left(\mu \mathrm{gC} \mathrm{mm}^{-3}\right.$ and $\mu \mathrm{g} \mathrm{N} \mathrm{mm}{ }^{-3}$; Fig. 5) and not per dry weight, because the dry weight of the pellets could not be measured with sufficient accuracy due to their low concentration. The concentration of organic carbon was $10.0 \mu \mathrm{g} \mathrm{mm}^{-3}$ at

Table 3. Fatty acid composition (\% of total fatty acids) of the faecal pellets during the dilution-decomposition experiment. SFA, MUFA, PUFA, BACFA: see Table 2 legend

\begin{tabular}{|lrrrr|}
\hline & SFA & MUFA & PUFA & BACFA \\
\hline Day 0 & 42.7 & 38.2 & 13.0 & 6.1 \\
Day 2.5 & 59.7 & 18.4 & 10.7 & 11.2 \\
Day 20 & 61.1 & 16.8 & 9.5 & 12.6 \\
\hline
\end{tabular}




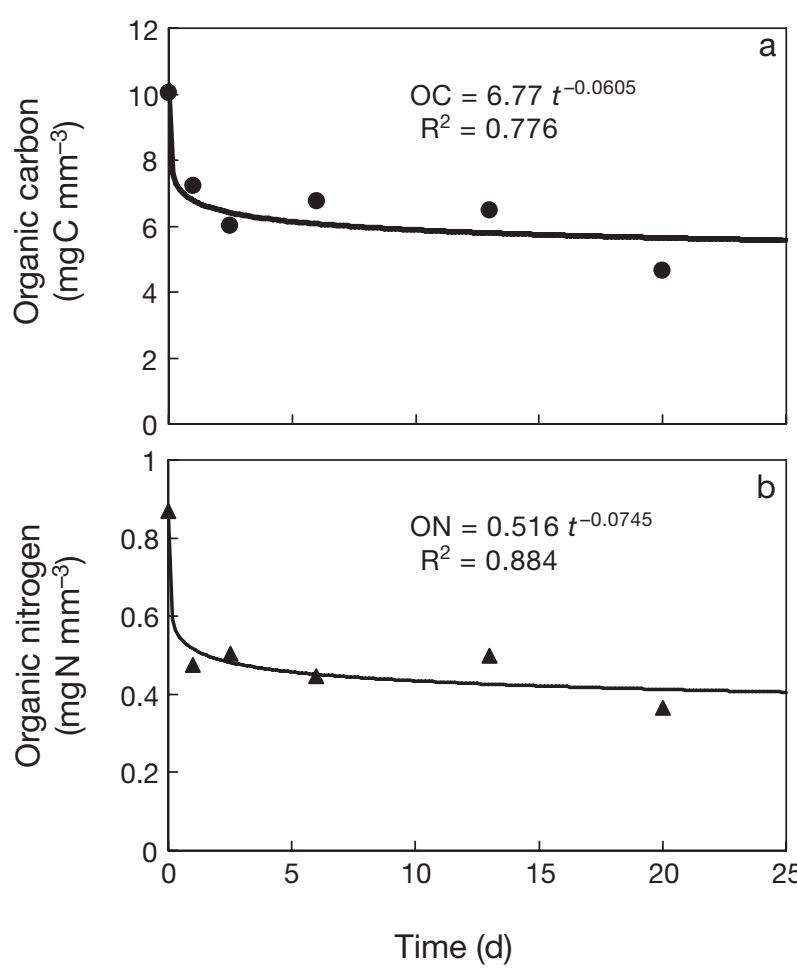

Fig. 5. Changes in concentrations of (a) organic carbon (OC) and (b) organic nitrogen $(\mathrm{ON})\left(\mathrm{mm}^{-3}\right)$ during dissolutiondecomposition experiment. Formulas represent results of regression analyses as an exponential function. $t=$ time (d)

the start of the experiment, and it rapidly decreased to $7.2 \mu \mathrm{g} \mathrm{C} \mathrm{mm} \mathrm{m}^{-3}$ on Day 1 (Fig. 5a). Thereafter, the carbon content gradually decreased to $4.7 \mu \mathrm{g} \mathrm{C} \mathrm{mm}^{-3}$ on Day 20. The nitrogen content in fresh pellets also showed a marked decrease on the first day from 0.87 to $0.47 \mu \mathrm{g} \mathrm{N} \mathrm{mm}{ }^{-3}$ (Fig. 5b). Little temporal change was noticed after Day 1, and a value of $0.37 \mu \mathrm{g} \mathrm{N}$ was measured on Day 20.

Both results clearly show that a considerable fraction of organic matter in the fresh faecal pellets was rapidly lost just after they were egested into the ambient waters. The remaining particulate organic fraction after Day 1, on the other hand, exhibited a rather refractory property, indicating that the pellets retain a significant amount of organic matter for at least 1 mo.

Drastic changes in fatty acid composition were observed during the dissolution-decomposition experiment. The contribution of UFA decreased with time, and that of MUFA was quite obvious from $38.2 \%$ on Day 0 to $16.8 \%$ on Day 20. SFA, on the contrary, complementarily increased from 42.7 (Day 0) to 61.1\% (Day 20). Interestingly, the contribution of BACFA increased 2-fold with the ongoing decomposition of faecal organic matter, indicating the relative increase in the bacterial biomass.

\section{DISCUSSION}

\section{Changes in organic composition}

In the Sargassum forest in Oura Bay, Amphipoda including Gammaridea and Caprellidea, Copepoda mainly composed of Porcellidium spp., and Gastropoda mainly composed of Tricolia megastoma Pilsbry are major constituents of mesograzers (M. N. Aoki unpubl. data). The sinking and precipitated pellets obtained in the present study were likely composed of these mesograzers, but microscopic observation of pellet size suggests that pellets egested from Amphipoda constitute a major part of the sinking and precipitated pellets; the individual epifaunal Porcellidium spp. and T. megastoma are considerably smaller (generally $<1 \mathrm{~mm}$ ) than the Amphipoda. However, some pellets from epifaunal Copepoda and Gastropoda might be included in our samples. Further, it is possible that faecal pellets of zooplankton are included in the precipitated pellets, though their contribution is likely negligible.

The analysis of the organic composition of the 3 types of faecal pellets served to elucidate the changes in the organic composition that accompany the progress of decomposition. The mean organic carbon and nitrogen content of the fresh pellets was 21.4 and $3.4 \%$ of dry weight, respectively. These values are roughly comparable with those of Arctic under-ice amphipods (Werner 2000). The contents of organic carbon and nitrogen tended to decrease in the following order: fresh, sinking and precipitated faecal pellets (Table 1), indicating that the egested faecal pellets were subject to degradation.

First, we discuss the early stage of degradation just after the pellets were egested by mesograzers. A striking difference in organic carbon content was found between the fresh and sinking pellets, probably due to the rapid compositional change during the time the sinking faecal pellets settled in the faecal trap: the trap was settled for 2 or $3 d$, so the mean age of the sinking pellets after egestion should be 1 to $1.5 \mathrm{~d}$. The dissolution-decomposition experiment showed that the organic carbon and nitrogen rapidly decreased on the first day (Fig. 5). Such a rapid decline in organic carbon content is comparable with the results of Urban-Rich (1999), who observed that about $40 \%$ of the organic carbon in fresh copepod pellets was lost within $6 \mathrm{~h}$ after the experiment began. This reduction in organic carbon content is probably due to the dissolution of dissolved organic carbon from the pellet and to microbial decomposition. Urban-Rich (1999) found that the rapid decrease in organic carbon from the fresh faecal pellets of copepods was mostly due to a decrease in the dissolved fraction, while the decrease in the particulate fraction was not significant. Such a rapid release of 
the dissolved fraction from fresh faeces has also been observed in other experiments (Jumars et al. 1989, Darchambeau et al. 2003, Møller et al. 2003). Those results indicate that the decrease in organic carbon just after egestion was mainly due to the dissolution of DOM from the faecal pellets.

A more severe change occurred in organic nitrogen. The larger decrease in organic nitrogen content than in organic carbon was in agreement with the results of our dissolution-decomposition experiment, in which the decrease in organic nitrogen on the first day was greater than that of organic carbon. These results, in turn, indicate that the organic matter lost just after the pellet was egested was composed of nitrogen-rich compounds compared with the bulk composition of the fresh pellets. Although the composition of organic nitrogen compounds was not examined in detail in the present study, it is quite probable that both free and combined amino acids were the main components (Cowie \& Hedges 1996). Since these nitrogenous organic compounds provide high-quality organic substrates for bacteria (Urban-Rich 1999, Bronk 2002), the DOM released from the egested pellets is most likely taken up quickly by bacteria, and plays an important role in the microbial food web.

The decompositional state of the egested faecal pellets can also be evaluated by their fatty acid composition. Fig. 6 illustrates the relationships between the contribution of UFA and that of BACFA. The fresh faecal pellets of mesograzers are characterized by the

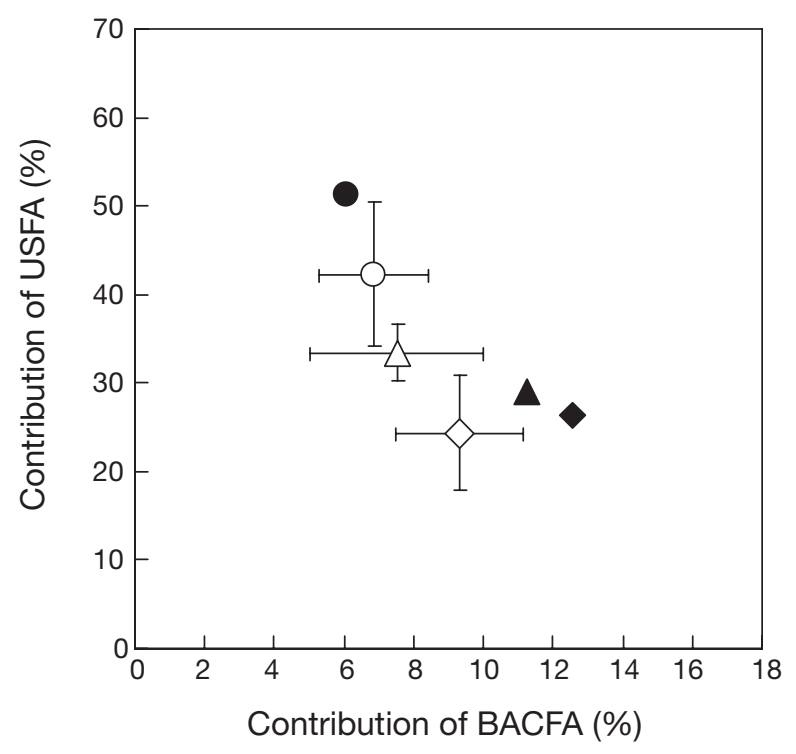

Fig. 6. Relationship between contributions of unsaturated fatty acids (UFA) and bacterial marker fatty acids (BACFA). O: fresh faecal pellets; $\Delta$ : sinking faecal pellets; $\diamond$ : precipitated faecal pellets; -: Day 0 ; $\boldsymbol{\Delta}$ : Day 2.5; $\bullet$ : Day 20 in dissolutiondecomposition experiment. Error bars represent SD highest contribution of UFA but the lowest BACFA. An increase in the bacterial biomass and a decrease in the UFA were observed for the sinking faecal pellets. The microbial decomposition of the lipid material is generally accompanied by a decrease in the contribution of UFA, which is more labile to microbial attack than SFA (Hama 1991, Wakeham \& Lee 1993, Fileman et al. 1998). The decrease in the relative contribution of UFA with the progress of decomposition has widely been observed in various biogeochemical samples, including sinking particles and sediments (De Baar et al. 1983, Wakeham \& Lee 1993, Fileman et al. 1998). The precipitated pellets were characterized by the lowest UFA and highest BACFA contributions, strongly suggesting that the microbial decomposition of faecal pellets took place on the sea floor.

These differences in fatty acid composition among the 3 types of faecal pellets were reproduced by the dissolution-decomposition experiment (Fig. 6). The contribution of BACFA increased over time with a reduction in the contribution of UFA. A considerable amount of labile organic matter for bacterial attack was probably supplied by the fresh faecal pellets during Days 0 and 2.5 as discussed above. Thus, it is possible that the increase in the bacterial biomass was maximal during this period, judging from the rapid increase in the contribution of BACFA. The shifting of the graphical position, however, was not drastic from Days 2.5 to 20, indicating that the increase in bacterial biomass was insignificant. This probably indicates that most of the labile organic carbon and nitrogen had been decomposed by Day 2.5 (Fig. 5), and that the bacterial growth was probably limited by the depletion of the labile organic matter after that time.

Apart from the phenomena that occurred just after the faecal pellets were egested by mesograzers, we will examine the degradation processes of organic matter in the faecal pellets a few days after egestion. Organic carbon and nitrogen, which remained in the faecal pellets a few days after egestion, showed no clear decreasing trend. The contents of organic carbon and nitrogen of the precipitated pellets were comparable with those of the sinking pellets (Table 1). Our dissolution-decomposition experiment also found slow declines in the concentrations of organic carbon and nitrogen after $2.5 \mathrm{~d}$ (Fig. 5). These results suggest that organic matter, which was neither released nor decomposed in the first few days, was relatively recalcitrant to bacterial attack. The low UFA:TFA ratio of the precipitated faecal pellets also indicates the relatively low lability of the organic matter in the precipitated faecal pellets. This relatively recalcitrant property of the non-fresh pellets is consistent with the results of Jacobsen \& Azam (1984), who determined that the decomposition rate of organic carbon in the faecal pellets of copepods was 
1 to $3 \% \mathrm{~d}^{-1}$; the results of our dissolution-decomposition experiment indicated that the daily decomposed fraction accounted for 0.7 to $0.9 \%$ of the concentration of organic carbon and nitrogen during Days 2.5 to 20. This, in turn, suggests that the precipitated faecal pellets retain organic carbon and nitrogen for time scales from weeks to months and indicates the possibility of the export of organic carbon and nitrogen outside the Sargassum forest together with the pellets, as will be discussed in the subsection 'Fate of organic matter...'.

\section{Relation to primary production of Sargassum forest}

This is probably the first time that the vertical flux of the faecal pellets produced by the epifaunal mesograzers was measured in field conditions. To elucidate the biogeochemical roles in the Sargassum forest, we will compare the vertical flux with the primary production of the Sargassum forest in Oura Bay. Mikami (2007) estimated the primary production of the same Sargassum forest in 2002 and reported the values of 2670 , 5960, 2390 and $3830 \mathrm{mg} \mathrm{C} \mathrm{m}^{-2} \mathrm{~d}^{-1}$ in October, January, May and August, respectively. The mean seasonal pellet fluxes are compared with the primary production in the corresponding seasons; the pellet fluxes potentially accounted for $7.4,10.7,9.5$ and $13.4 \%$ of the primary production of Sargassum forest in autumn, winter, spring and summer, respectively. These comparisons indicate that about $10 \%$ of the primary production in Sargassum forest may be vertically transported to the sea floor by faecal pellets of epifaunal mesograzers.

Although Mikami (2007) determined the primary production of Sargassum using algae with a small epiphytic diatom, it is impossible to measure the production due specifically to Sargassum spp. On the other hand, the microscopic observation of faecal pellets of mesograzers indicates that mesograzers consume the epiphyte as well as Sargassum spp. to some extent. Thus, the relationship between primary production and faecal flux obtained here likely includes the primary production and consumption of the epiphyte as well as Sargassum spp., though contribution of the former is likely insignificant. The measurements of primary production were done in a different year from the determination of the pellet fluxes; however, minimal change in the Sargassum biomass (Mikami 2007, M. N. Aoki pers. obs.) suggests the temporal disagreement probably does not cause serious error in the contribution of pellet flux to primary production.

The production of organic nitrogen in the Sargassum forest is estimated as 155, 347, 139 and $223 \mathrm{mg} \mathrm{N} \mathrm{m}^{-2}$ $\mathrm{d}^{-1}$ in autumn, winter, spring and summer, respectively, by applying the average C:N ratio of $S$. ring- goldianum (17.2). The vertical fluxes of organic nitrogen of pellets correspond to 9.4, 15.2, 16.5 and $20.3 \%$ of primary production in autumn, winter, spring and summer, respectively. The average contribution of $15.4 \%$ of organic nitrogen was considerably higher than that of organic carbon, due to the lower C:N ratio of the faecal pellets than that of $S$. ringgoldianum.

Having estimated the proportion of the pellet flux to primary production, we will now examine the validity of the pellet flux in detail. The pellet flux was determined by 4 observations in the present study, and it might be insufficient to recognize those as the representative value in each season. However, less variability in the contribution of pellet flux to the primary production $($ mean $=10.2 \pm 2.3 \%$ SD for carbon, and $15.2 \pm$ $4.4 \%$ for nitrogen), strongly suggests that the pellet fluxes basically depended on the primary production of Sargassum forest.

Resuspension of the precipitated pellets is one of the primary factors which affect the pellet flux. In winter, especially, it is conceivable that resuspension of the precipitated pellets occurs due to the rough water conditions caused by high wind speeds. To elucidate this possibility, we compare the fatty acid composition of the sinking and precipitated pellets in detail. The most striking difference in fatty acid composition was noticed for MUFA, which accounted for 25.1 to $28.8 \%$ of TFA in the sinking pellets and 14.9 to $26.0 \%$ in the precipitated pellets. Except in summer, the contribution of MUFA in the precipitated pellets (14.9 to $21.5 \%$ ) was markedly lower than in the sinking pellets by 6.0 to $13.6 \%$. This compositional difference between sinking and precipitated pellets strongly suggests that the resuspension of the precipitated pellets is not serious in autumn, winter and spring. In summer, on the other hand, the difference was minimal, indicating the possible effect of resuspended pellets on the flux. The highest value of the pellet flux to the primary production in summer also indicates some overestimation of the vertical flux of faecal pellets.

Dissolution and/or decomposition of organic matter (Lee \& Fisher 1994), including coprophagy (ingestion of fecal pellets) and coprochaly (disruption of peritrophic membranes) (Noji et al. 1991, Turner 2002) just after the pellets were egested, are other factors affecting the estimation of the pellet flux. We settled pellet traps for 2 to $3 \mathrm{~d}$ to collect enough pellets for chemical analysis, and our dissolution-decomposition experiment suggests that a part of the organic carbon and nitrogen is lost after the pellets were settled into the trap vessels. By assuming that the pellet flux is constant during the settlement of the pellet traps, we can evaluate the effect of the dissolution and/or decomposition on the flux measured by using the results of the dissolution-decomposition experiment (Fig. 5). The 
integration of the regression curve of organic carbon or nitrogen in the pellets from Day 0 to Day 2 or 3 corresponds to the remaining fraction of the settled organic carbon and nitrogen in the trap vessels. The ratios of the integrated values to the 'real' flux, which is assumed not to suffer a loss, are calculated to be 0.67 to 0.69 for organic carbon and $0.58-0.60$ for nitrogen for the 2 to $3 \mathrm{~d}$ settlement. This indicates that the flux measured in the present study underestimates the 'real' flux by 30 to $40 \%$. As for the possible loss of organic matter during the settling of the trap, the fluxes of organic carbon and nitrogen increased to $338-954 \mathrm{mgC} \mathrm{m}^{-2} \mathrm{~d}^{-1}$ and $25.9-91.3 \mathrm{mg} \mathrm{N} \mathrm{m}^{-2} \mathrm{~d}^{-1}$, respectively, accounting for $11-19 \%$ and $17-34 \%$ of the concurrent primary production of organic carbon and nitrogen, respectively.

The degree of the possible underestimation of the pellet flux may be increased when we consider that the age of the fresh pellet used for the dissolution-decomposition experiment was $0.5 \mathrm{~d}$. The rapid dissolution of organic matter from pellets just after the egestion observed in the previous studies (Lee \& Fisher 1994, Urban-Rich 1999) and the present study, suggest that the fresh pellets likely lost a part of organic matter before they were collected from the culture of mesograzers.

The efficiency of the collection of sinking particles reportedly depends on the shape of the sediment trap, especially on the aspect ratio (height:mouth opening) (Hargrave \& Burns 1979). Although it is likely that the aspect ratio (1.8) of the trap used in the present study efficiently collected the sinking faecal pellets in calm conditions, the efficiency may considerably decrease with an increase in current speed (Hargrave \& Burns 1979, Baker et al. 1988). Since we have no information of the current speed at the trap site in the Sargassum forest, the trap efficiency in each observation cannot be quantified. However, the measured pellet fluxes are probably underestimated with regard to the aspect ratio of the trap when we consider that tidal current may affect trap efficiency.

No information is available to compare the importance of the vertical flux of faecal pellets in the seaweed beds, but comparisons were made between the primary production (and/or algal biomass) and the consumption by the grazers. The grazing pressure of herbivores on the seaweed reportedly varied from a few to $80 \%$ of the primary production of seaweed (Cebrian 2004). Although grazing rate was not directly measured in the present study, it can be roughly estimated by applying the ratio of the faecal production to the consumption of kelp by mesograzers $(72 \%$; Koop et al. 1982). Thus, the grazing rate by epifaunal mesograzers on Sargassum ringgoldianum is calculated to be 278 to $889 \mathrm{mg} \mathrm{C} \mathrm{m}^{-2} \mathrm{~d}^{-1}$, which accounts for 10 to
$18 \%$ of the daily primary production of $S$. ringgoldianum. Although both the percentage and the absolute grazing rate are within the range summarized by Cebrian (2004), they are much lower than the average values estimated for seaweed ecosystems. Higher levels of consumption were mainly observed in ecosystems where sea urchins were the dominant grazers (Hauxwell et al. 1998). However, it is known that amphipods sometimes exert a strong impact on the algal biomass and the organization of an algal community through their grazing activity (Hauxwell et al. 1998, Duffy \& Hay 2000). These studies strongly suggest that the sinking fluxes of faecal pellets released from mesograzers in the seaweed beds are generally higher in such seaweed ecosystems. Thus, the faecal pellets likely play an important role in the biogeochemical cycle in the seaweed beds as well as in the pelagic ocean.

\section{Fate of organic matter in precipitated faecal pellets}

The concentration of the precipitated faecal pellets ranged from 3.4 to $14 \mathrm{~g} \mathrm{C} \mathrm{m}^{-2}$ (mean $=7.14 \mathrm{~g} \mathrm{C} \mathrm{m}^{-2}$ ) and from 0.36 to $0.98 \mathrm{~g} \mathrm{~N} \mathrm{~m}^{-2}$ (mean $=0.55 \mathrm{~g} \mathrm{~N} \mathrm{~m}^{-2}$ ) for organic carbon and organic nitrogen, respectively (Fig. 4). A comparison of the sinking flux to the precipitated concentrations yields the residence time of the organic matter of precipitated faecal pellets. Here we use the fluxes and precipitated pellets in each season, and the residence time varied from 9 to $27 \mathrm{~d}$ for carbon and from 8 to $25 \mathrm{~d}$ for nitrogen. These estimations indicate that the turnover of precipitated pellet by the sinking flux takes a week to a month. These findings lead us to ask: Were the organic carbon and nitrogen in the precipitated pellets decomposed and/or dissolved on the sea floor of the seaweed beds within these residence times?

When we assume that the decomposition of the organic matter in the precipitated pellets follows the formulas obtained in the dissolution-decomposition experiments (Fig. 5), the remaining organic fractions in the pellets at the end of the residence time account for 55 to $59 \%$ and 47 to $51 \%$ of the sinking fluxes for organic carbon and nitrogen, respectively. In other words, about half of the organic matter precipitated onto the sediment would not be decomposed within the Sargassum forest. The microscopic observation of the sand layer under the pellet layer covering the sea floor of the Sargassum forest (Fig. 2b) showed only a small amount of pellets buried in the deeper layer.

It is possible that the remaining organic matter was laterally exported outside the Sargassum forest. It is occasionally observed (M. N. Aoki pers. obs.) that the 
seawater in Oura Bay shows a high turbidity and is brownish in color during rough conditions. This turbidity extends from the bottom to the water surface, indicating that the suspended particles have a relatively low specific gravity. Microscopic observations revealed that the suspended particles causing the turbidity were mainly due to faecal pellets resuspended from the seafloor by water mixing. Since Oura Bay opens out to the open ocean (Fig. 1), exchanges frequently occur between the bay water and the open ocean water. Thus, it is likely that the resuspended faecal pellets were laterally exported beyond Oura Bay. The undecomposed fractions of the faecal pellets at the end of the residence time of precipitated pellets can be estimated as 109 to $379 \mathrm{mg} \mathrm{C} \mathrm{m}^{-2}$ (55 to $59 \%$ of the carbon flux) and 6.8 to $27 \mathrm{mg} \mathrm{N} \mathrm{m}^{-2} \mathrm{~d}^{-1}$ (47 to $51 \%$ of the flux), and are potentially laterally exported. The potential export flux of organic matter accounts for 4.1 to $7.4 \%$ $($ mean $=5.8 \%)$ and 4.4 to $9.5 \%$ (mean $=7.4 \%$ ) of the concurrent Sargassum primary production of organic carbon and nitrogen, respectively.

No study has elucidated the export flux of organic matter by the faecal pellets of epifaunal herbivores outside of the seaweed beds. Cebrian (1999) examined the reported values of primary production and export of the plant materials (including phyto-detritus), and found that the export flux from seaweed ecosystems beyond the community boundaries varied from 10 to $10000 \mathrm{mg} \mathrm{C} \mathrm{m}^{-2} \mathrm{~d}^{-1}$, though the quantitative relationship between the export flux and the primary production was obscure; the export/NPP ratio reportedly varied from 0 to $100 \%$ (Cebrian 1999). The export carbon flux as faecal pellets estimated in the present study (109 to $379 \mathrm{mg} \mathrm{C} \mathrm{m}^{-2} \mathrm{~d}^{-1}$ ) is roughly comparable to the reported average export flux of plant materials from seaweed beds. This compatibility strongly suggests that the faecal pellets are important vehicles of the export of organic matter from the seaweed beds. The fraction of primary production consumed by the epifaunal herbivores estimated in the present study is lower than the average value of the seaweed beds (Cebrian 2004) as discussed above. The role of faecal pellets in the geochemical cycle in seaweed beds and their adjacent areas most likely increases with an increase in the fraction consumed by herbivores. Although the biogeochemical importance of the faeces of sea urchins in seaweed beds has been suggested (Mamelona \& Pelletier 2005), little research has been done on the faecal pellets of the mesograzers living there. Further studies including the determination of production, decomposition and export fluxes of the faecal materials in various seaweed beds will elucidate their biogeochemical roles in the coastal benthic ecosystems, as has already been established in the pelagic ocean.
Acknowledgements. This study was supported by a grant from the Ministry of Education, Culture, Sports, Science and Technology, Japan (No. 15651002). This report is contribution no. 732 from the Shimoda Marine Research Center, University of Tsukuba.

\section{LITERATURE CITED}

Alongi DM (1998) Coastal ecosystem processes. CRC Press, Boca Raton, FL

Baker ET, Milburn HB, Tennant DA (1988) Field assessment of sediment trap efficiency under varying flow conditions. J Mar Res 46:573-592

Boschker HTS, de Brouwer JFC, Cappenberg TE (1999) The contribution of macrophyte-derived organic matter to microbial biomass in salt-marsh sediments: stable carbon isotope analysis of microbial biomarkers. Limnol Oceanogr 44:309-319

Brawley SH (1992) Mesoherbivores. In: John DM, Hawkins SJ, Price JH (eds) Plant-animal interactions in the marine benthos. Clarendon Press, Oxford, p 235-263

Bronk DA (2002) Dynamics of DON. In: Hansell DA, Carlson CA (eds) Biogeochemistry of marine dissolved organic matter. Academic Press, San Diego, CA, p 153-247

Cebrian J (1999) Patterns in the fate of production in plant communities. Am Nat 154:449-468

Cebrian J (2004) Grazing on benthic primary producers. In: Nielsen SL, Banta GT, Pedersen MF (eds) Estuarine nutrient cycling: the influence of primary producers. Kluwer Academic Publishers, Dordrecht, p 153-185

Cowie GL, Hedges JI (1996) Digestion and alteration of the biochemical constituents of a diatom (Thalassiosira weissflogii) ingested by an herbivorous zooplankton (Calanus pacificus). Limnol Oceanogr 41:581-594

Darchambeau F, Faerovig PJ, Hessen DO (2003) How Daphnia copes with excess carbon in its food. Oecologia 136: 336-346

De Baar HJW, Farrington JW, Wakeham SG (1983) Vertical flux of fatty acids in the North Atlantic Ocean. J Mar Res 41:9-41

Duffy JE (1990) Amphipods on seaweeds: partners or pests? Oecologia 83:267-276

Duffy JE, Hay ME (2000) Strong impacts of grazing amphipods in the organization of a benthic community. Ecol Monogr 70:237-263

Edgar GJ, Aoki M (1993) Resource limitation and fish predation: their importance to mobile epifauna associated with Japanese Sargassum. Oecologia 95:122-133

Edgar GJ, Moore PG (1986) Macro-algae as habitats for motile macrofauna. Monogr Biol 4:255-277

Fileman TW, Pond DW, Barlow RG, Mantoura RFC (1998) Vertical profiles of pigments, fatty acids and amino acids: evidence for undegraded diatomaceous material sedimenting to the deep ocean in the Bellingshausen Sea, Antarctica. Deep-Sea Res 45:333-346

Frangoulis C, Christou ED, Hecq JH (2005) Comparison of marine copepod outfluxes: nature, rate, fate and role in the carbon and nitrogen cycles. Adv Mar Biol 47:253-309

Graeve M, Dauby P, Scailteur Y (2001) Combined lipid, fatty acid and digestive tract content analyses: a penetrating approach to estimate feeding modes of Antarctic amphipods. Polar Biol 24:853-862

Hama T (1991) Production and turnover rates of fatty acids in marine particulate matter through phytoplankton photosynthesis. Mar Chem 33:213-227

Hargrave BT, Burns NM (1979) Assessment of sediment trap collection efficiency. Limnol Oceanogr 24:1124-1136 
Hauxwell J, McClelland J, Behr PJ, Valiela I (1998) Relative importance of grazing and nutrient controls of macroalgal biomass in 3 temperate shallow estuaries. Estuaries 21: $347-360$

Jacobsen TR, Azam F (1984) Role of bacteria in copepod fecal pellet decomposition: colonization, growth rates and mineralization. Bull Mar Sci 35:495-502

Jumars PA, Penry DL, Baross JA, Perry MJ, Frost BW (1989) Closing the microbial loop: dissolved carbon pathway to heterotrophic bacteria from incomplete ingestion, digestion and absorption in animals. Deep-Sea Res 36:483-495

Koop K, Newell RC, Lucas MI (1982) Biodegradation and carbon flow based on kelp (Ecklonia maxima) debris in a sandy beach microcosm. Mar Ecol Prog Ser 7:315-326

Lee BG, Fisher NS (1994) Effects of sinking and zooplankton grazing on the release of elements from planktonic debris. Mar Ecol Prog Ser 110:271-281

Mamelona J, Pelletier E (2005) Green urchin as a significant source of fecal particulate organic matter within nearshore benthic ecosystems. J Exp Mar Biol Ecol 314:163-174

Mikami A (2007) Estimating the net primary production of Sargassum species (Phaeophyceae) throughout different life stages: from fixation to drifting. $\mathrm{PhD}$ thesis, University of Tokyo

Møller EF, Thor P, Nielsen TG (2003) Production of DOC by Calanus finmarchicus, C. glacialis and C. hyperboreus through sloppy feeding and leakage from fecal pellets. Mar Ecol Prog Ser 262:185-191

Noji TT, Estep KW, Macintyre F, Norrbin F (1991) Image analysis of faecal material grazed upon by three species of copepods: evidence for coprorhexy, coprophagy and coprochaly. J Mar Biol Assoc UK 71:465-480

Norton TA, Benson MR (1983) Ecological interactions between the brown seaweed Sargassum muticum and its associated fauna. Mar Biol 75:169-177

Editorial responsibility: Howard Browman (Associate Editorin-Chief), Storebø, Norway
Sand-Jensen K, Nielsen SL (2004) Estuarine primary producers. In: Nielsen SL, Banta GT, Pedersen MF (eds) Estuarine nutrient cycling: the influence of primary producers. Kluwer Academic Publishers, Dordrecht, p 17-57

Sundquist ET (1993) The global carbon dioxide budget. Science 259:934-941

Tanaka MO, Leite FPP (2003) Spatial scaling in the distribution of macrofauna associated with Sargassum stenophyllum (Mertens) Martius: analyses of faunal groups, gammarid life habits, and assemblage structure. J Exp Mar Biol Ecol 293:1-22

Taylor RB (1998) Density, biomass and productivity of animals in four subtidal rocky reef habitats: the importance of small mobile invertebrates. Mar Ecol Prog Ser 172: $37-51$

Taylor RB, Rees TAV (1998) Excretory products of mobile epifauna as a nitrogen source for seaweeds. Limnol Oceanogr 43:600-606

Turner JT (2002) Zooplankton fecal pellets, marine snow and sinking phytoplankton blooms. Aquat Microb Ecol 27: 57-102

Urban-Rich J (1999) Release of dissolved organic carbon from copepod fecal pellets in the Greenland Sea. J Exp Mar Biol Ecol 232:107-124

Wakeham SG, Lee C (1993) Production, transport and alternation of particulate organic matter in the marine water column. In: Engel MH and Macko SA (eds) Organic geochemistry, principles and applications. Plenum Press, New York, p 145-169

Werner I (2000) Faecal pellet production by Arctic under-ice amphipods: transfer of organic matter through the ice/ water interface. Hydrobiologia 426:89-96

Yokohama Y, Tanaka J, Chihara M (1987) Productivity of the Ecklonia cava community in a bay of Izu Peninsula on the Pacific coast of Japan. Bot Mag Tokyo 100:129-141

Submitted: November 3, 2006; Accepted: July 20, 2007

Proofs received from author(s): December 7, 2007 